\title{
Marginal Bone Level Changes and Oral Health Impact Profile (14) Score of Smokers Treated by Mandibular Mini Implant Overdentures: A 5-Year Follow-up Study
}

\author{
Mostafa Omran Hussein ${ }^{1, \odot}$ Mohammed Suliman Alruthea ${ }^{1}$ \\ ${ }^{1}$ Department of Prosthodontic Sciences, College of Dentistry in $\mathrm{Ar}$ \\ Address for correspondence Mostafa Omran Hussein, BDS, MS, \\ Rass, Qassim University, Saudi Arabia \\ PhD, Department of Prosthodontic Sciences, College of Dentistry in \\ Ar Rass, Qassim University, Saudi Arabia \\ (e-mail: m.omran@qu.edu.sa).
}

Eur J Dent:2020;14:590-597

\begin{abstract}
Objectives Studies considered edentulous patients having smoking habit as a compromised oral condition. This research examined the value of using mini implant mandibular overdenture to maintain long-term satisfactory levels of oral health quality of life and marginal vertical bone loss.

Materials and Methods Twenty-nine edentulous patients with smoking habit received four mini implants in the mandible loaded by overdentures. The present study monitored patients radiographically for vertical bone loss after (1 month, 1, 3, and 5 years) of treatment. Patients were also evaluated by oral health impact profile 14 (OHIP-14) pretreatment and at 1 and 5 years of treatment.

Statistical Analysis Repeated measure analysis of variance with Bonferroni's test as a post-hoc test was used to see the difference among time points. Independent sample $t$-tests were used to compare between anterior and posterior mini implant positions after 5 years of follow-up. OHIP-14 questionnaire was analyzed by Wilcoxon signed ranks for pairwise comparisons at different evaluation times. A Holm-Bonferroni correction method was used to control the familywise error rate.

Results The mean of the bone height changes showed a significant difference between 1-month data and all other evaluation intervals while no significance was cal-

Keywords

- marginal bone loss

- mini implant overdenture

- OHIP-14

- oral health-related quality of life

- smoking habit culated among other evaluation intervals. Bone loss of the mini implants placed anteriorly was less than those placed posteriorly with a statistically significant difference. A significant reduction in the OHIP-14 score levels was observed between pretreatment and both 1 and 5 years of treatment. No significance was seen between the first and fifth year after treatment.

Conclusion Mini implant overdenture could maintain satisfactory marginal bone level changes and oral health quality of life for patients with smoking habit after 5-year follow-up period.
\end{abstract}

\section{Introduction}

Mini implant supported over denture is an effective treatment with minimally invasive measures. Stabilizing the conventional dentures by mini implants was clearly described and documented as a definitive treatment. ${ }^{1-3}$ Article reviews concluded that mini implants could be used safely to retain removable prosthesis, especially if all other parameters such as bone quality, anatomical locations, protective occlusal schemes are maintained. Because of their merits, it was not surprising to have an encouraging value (94.7\%) of survival rate., 
Studies revealed that several factors might affect implant success encompassing bruxism, insertion torque, smoking, and mechanical overload.

Particularly, smoking was studied for years as a compromising healing factor for mucogingival tissues and bones, and might be a predisposing factor to several gingival and periodontal conditions. ${ }^{6-10}$ In addition, it might also affect the implant failure rate, peri-implant marginal bone level and accompanied with a higher incidence of complications. ${ }^{6,11,12}$

The mean values of bone loss and implant survival rate were monitored in several researches as reliable parameters for implant success in patients with smoking habit. ${ }^{11-15}$ Accordingly, Peñarrocha et al, ${ }^{11}$ monitored peri-implant marginal bone loss in a patient's cohort and confirmed their relations to smoking habit, implant position, and morphology. Furthermore, a systemic review and meta-analysis, concluded that smoking had a negative effect on peri-implant tissue integrity and could be listed as a factor initiating peri-implantitis. ${ }^{6}$ This negative effect was recorded in both implant supported fixed prosthesis and implant overdenture of smokers. ${ }^{9,14,16}$

Many researches adopted patients' satisfaction and oral health-related quality of life as major tools for prosthesis assessment. ${ }^{17-24}$ These researches used satisfaction questionnaires to test patients' mini implant overdenture perception, satisfaction, and prosthetic maintenance aspects for intervals ranging from 3 to 7 years. In addition, visual analogue scale was used to augment some of these questionnaires to enhance reliability. ${ }^{18,19}$ Moreover, researchers believed that oral health impact profile (OHIP) is a reliable measure for oral health-related quality of life (OHRQoL) of different prosthetic options. ${ }^{21,23,24}$ One of the popular versions used to study implant overdentures was the short version of the oral health impact profile-14 (OHIP-14).23,24

Completely edentulous patients with smoking habit may suffer more than normal patients from the deleterious effect of smoking, leading to bone loss and unsatisfactory oral health quality of life. Mini implant overdenture is a successful treatment and could be considered as a standard health care for completely edentulous patients.,55,18 Accordingly, this study was conducted to evaluate the use of the mini implant mandibular overdenture, as a definitive, stable line of treatment capable to enhance oral health quality of life, in a cohort of smokers within 5 years of function. No study was conducted to reveal the value of using mini implants to retain complete dentures of smokers. Consequently, the marginal peri-implant bone loss as well as the (OHRQoL) was assessed radiographically and by OHIP-14 over 5-years of follow-up period, respectively. The study hypothesized that a significant difference, in vertical bone level and OHIP-14 score, will be seen between different evaluation times throughout the 5 years of the study.

\section{Materials and Methods}

\section{Study Design}

An eligibility assessment was done for 43 patients using the inclusion criteria. Accordingly, 29 male complete denture wearers, with age range 45 to 60 years, were enrolled in the study based on the predetermined inclusion criteria ( - Fig. 1). These patients were selected from a cohort of smoking patients ( $\geq 10$ cigarettes/d) with continuous smoking habits for at least 2 years before current study. ${ }^{10}$ These patients were selected from outpatient clinic at Alrass Dental College, Qassim University based on their chief complain of mandibular denture retention and stability. Both radiographic and clinical examination as well as their medical records were checked to ensure the adequate bone volume and soft tissue quality required for mini implant placement (at least $3.5 \times 10 \mathrm{~mm}$ size). Arch relationship was limited to class I and adequate restorative space was maintained in the interarch distance (minimum $15 \mathrm{~mm}$ ). All patients were systemically free from any disease affecting bone healing and implant treatment. ${ }^{3}$ The demographic characteristics of participants included: age $($ mean $)=56$, gender (all males), marital status ( married $=25$, single $=4$ ), and employment (employed $=26$, unemployed $=3$ ). The power sample of the study was calculated by G*Power software for windows and using effective size $\mathrm{d} z=0.5,=0.05$ as error probability and a power of sample (0.88) (1-error probability). This study adopted

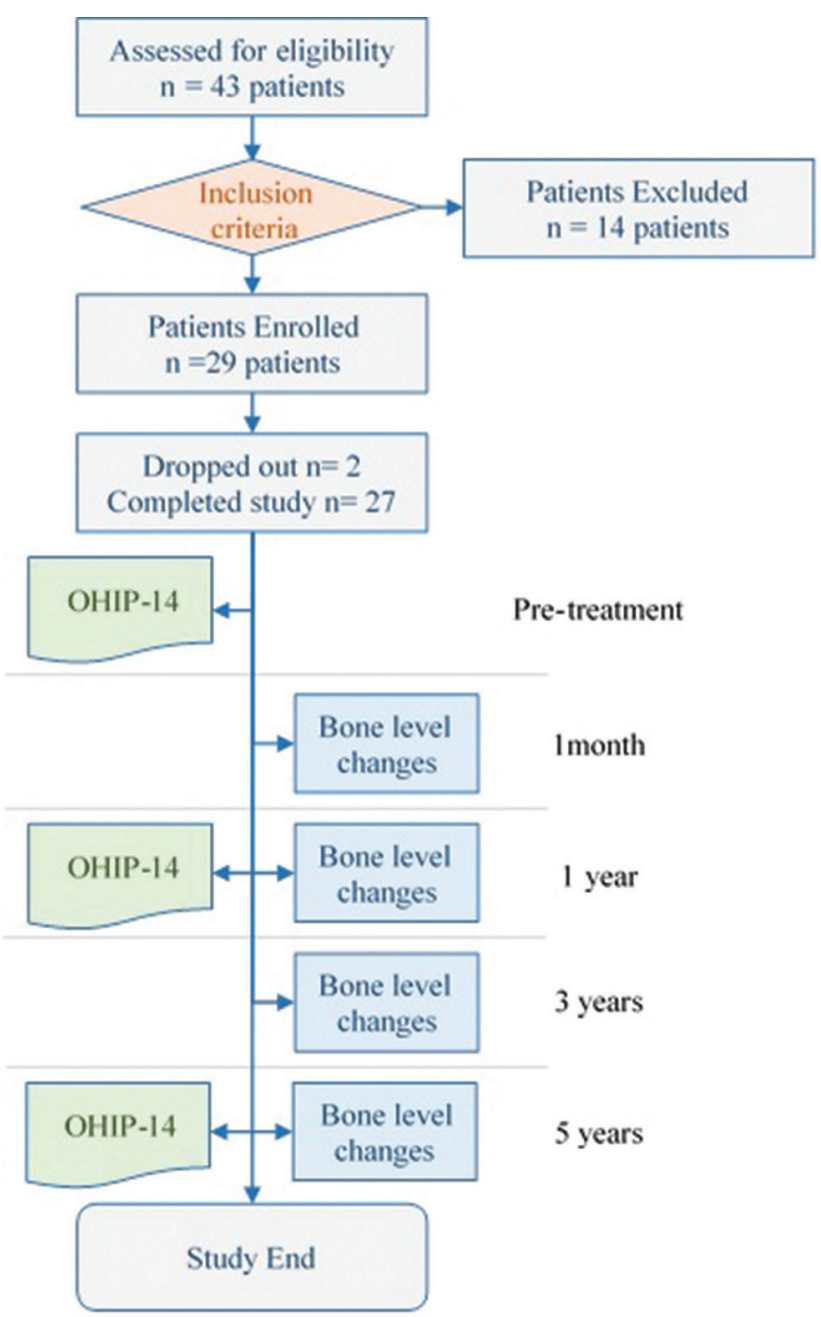

Fig. 1 Flowchart of study design including participants' enrolment and assessment intervals for marginal bone height changes and (OHIP-14). 
the CONSORT guidelines for clinical studies. The study was approved by the Ethical Committee of the Research Center of the Faculty of Dentistry Qassim University.

Mandibular mini implant overdenture opposing maxillary complete denture was considered as a treatment modality. All patients signed the informed consent after explanation of the proposed treatment and follow-up. Each patient was planned to receive four mini implants (MDI mini implants; 3M ESPE, United States), to retain their overdentures. The implant diameter used was $2.1 \times 13 \mathrm{~mm}$.

Twenty-nine complete dentures were constructed and checked in the patients' mouth for any complaints. After 10 days, the patients were recalled for their surgical phase after confirming that all post-insertion complaints were resolved. Implant site preparation was performed according to specific surgical and prosthetic considerations. Accordingly, distal implants were planned to be placed with a minimum of 5-mm mesial to the mental foramen, and a minimum of $5 \mathrm{~mm}$ was left between each implant to allow space for their housings. Subsequently, these positions were transferred to the gingiva as bleeding points. Flapless implant placement followed by immediate loading was considered as a treatment protocol.

Drilling was started by the pilot drill (1.1-mm diameter) under profuse sterile irrigation at the preplanned positions. The implant was inserted in clockwise direction until engaging a bone resistance with a subsequent seating by the winged thumb driver. A final seating was performed with the torque-controlled ratchet wrench at $35 \mathrm{~N} / \mathrm{cm}$ precustomized torque ( - Fig. 2A).

Once all implants were placed, the mandibular denture were prepared to receive housings. The polyvinyl chloride
(PVC) tubes were trimmed to fit the implants' necks to block undercuts in the ball attachment beneath the metal housing. The metal housings were loaded with the rubber rings and then seated over the implant balls ( $\mathbf{- F i g . ~ 2 B}$ ). The relieved fitting surfaces of the denture were checked at the implants' sites to ensure enough room for metallic housings. The denture holes were painted with the acrylic adhesive, then a cold cured acrylic hard liner was injected in the relieved holes followed by seating in the patient's mouth with a minimal occlusal pressure. After 5 minutes, the denture was removed to trim excess material followed by the removal of PVC tubes. The fitting surface of the denture was checked for any material deficiency around the housings ( - Fig. 2C). Occlusion was rechecked by articulating paper to ensure passive seating.

\section{Radiographic Evaluation}

All patients were scheduled at recall visits for follow-up and collecting data. All radiographic records (parallel digital periapical imaging) were performed and data were collected using long cone attachment holder with an acrylic resin template customized for each patient. After digitization, the measurements were calibrated by calculating the difference between the actual mini implant length and their length on the X-ray. The level of peri-implant vertical bone level changes was measured on the mesial and distal sides of the implant from the polished platform level to the first visible marginal crestal level and the average was calculated ${ }^{11,25,26}$ ( - Fig. 2D). All measurements were done by independent radiologist recruited for digital measurements who was unaware about the research objectives. Intraclass correlation coefficient was calculated to evaluate the intraobserver reliability. In addition, to avoid the observer bias, all records for the marginal
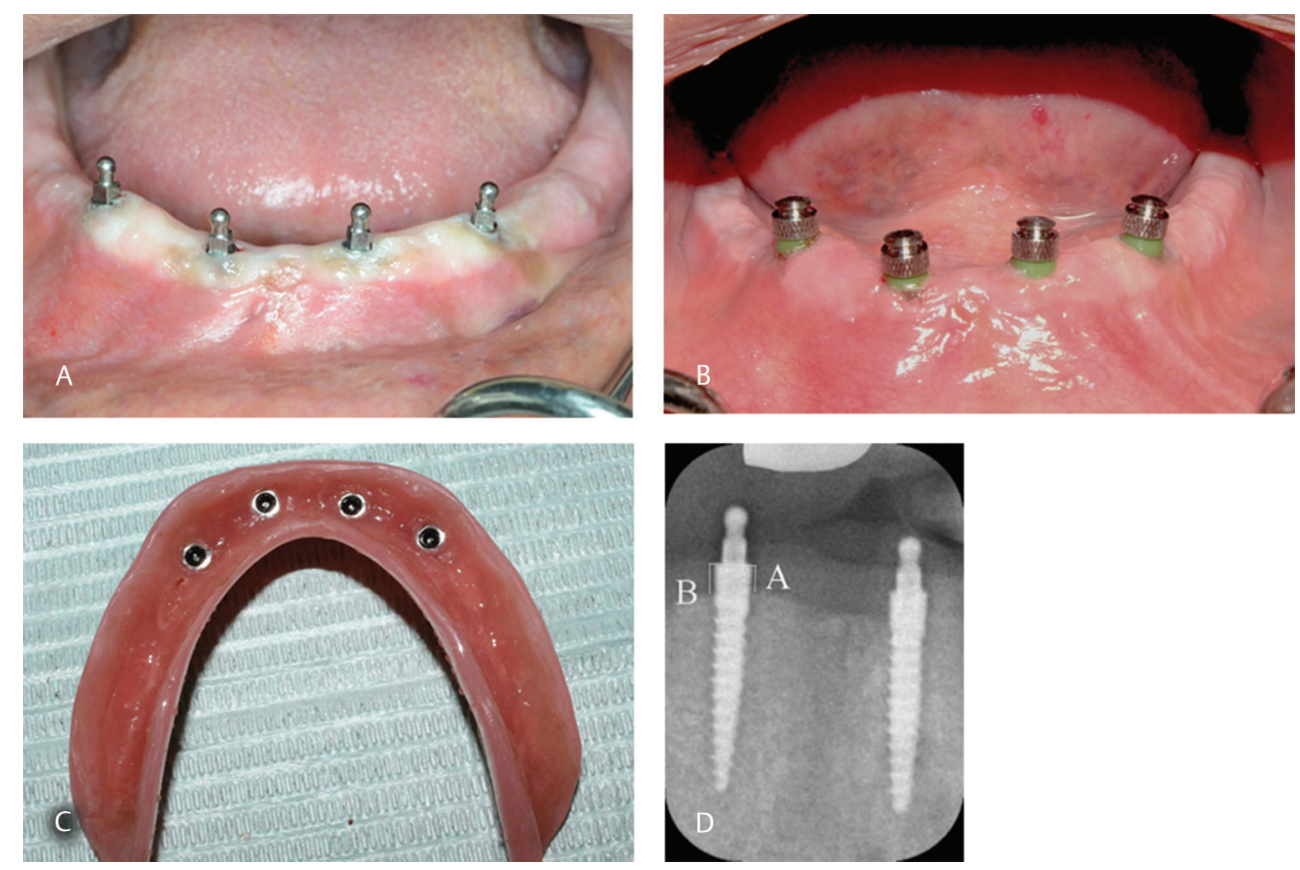

Fig. 2 (A) Four mini implants finally seated at $35 \mathrm{~N} / \mathrm{cm}$ torque using ratchet wrench with the ball attachment suprastructure at the mandibular parasymphyseal area. (B) Loaded metal housing fitted over mini implants after placing rubber shims tubes (green color) to block undercuts during pick-up process. (C) Fitting surface of the overdenture after pick-up of the attachment and acrylic flash removal. (D) Digital periapical radiograph of mini-implants and their surrounding bone used for peri-implant bone height measurements, A-mesial measurement and Bdistal measurement. 
bone change were measured twice by one observer within 10 days period between measurements.

The peri-implant crestal bone level at the time of loading was used as a baseline for all postoperative measurements. Changes in the vertical bone levels at each observation time, 1 month, and at 1,3 , and 5 years after loading ( 1 month, 1, 3, and 5 years), were calculated by subtracting corresponding baseline bone levels.

After clinical and radiographic examination, the data were also distributed and segregated according to mini implant positions in the arch. The condition of each mini implant was evaluated according to predetermined criteria suggested by the International Congress of Oral Implantology at the 2007 consensus conference. ${ }^{27}$ Each implant status was represented as failed, compromised survival, satisfactory survival, or successful according to criteria mentioned in - Table 1.

\section{Statistical Analysis}

All data of the 108 mini implants were collected and then statistically analyzed using s-plus statistical software (SPSS). Kolmogorov-Smirnov test was used to test data normality. Descriptive data analyses included mean value and standard deviation for parametric variables. Repeated measure analysis of variance with Bonferroni's test as a post-Hoc test was used to see difference among time points. Independent sample $t$-tests were used to compare between anterior and posterior mini implant positions after 5 years of follow-up. A $p$-value $<0.05$ was considered as statistically significant.

\section{Oral Health-Related Quality of Life}

OHRQoL of mini implant overdenture treatment was assessed using short version of OHIP-14 pretreatment and at 1 and 5 years of service. The questionnaire was composed of seven dimensions each one has two items to form 14 questions (OHIP-14). The seven dimensions of the questionnaire include limitation of the function (D1), pain (D2), psychological discomfort (D3), physical (D4) and psychological disability (D5), social disability (D6), and handicap (D7). Responses to this scale are based on a Likert format with a five-point ordinal scale (never [0], hardly ever [1], occasionally [2], fairly often [3], and very often [4]; - Table 2). The questionnaire template was explained and delivered to the patients and all data were collected for all patients to calculate the score later. ${ }^{21}$ OHIP-14 domain scores were calculated by collating responses to items in each domain, and total OHIP-14 value was calculated by collating the said domain scores. Total OHIP-14 scores range is $0-56$. The higher the score, the poorer would be OHRQoL. The scores of the patients were collected before treatment and at 1 and 5 years. The data collected were checked for normality using Shapiro-Wilk test. The data were nonparametric so a repeated measure analysis was calculated by the Freidman's test followed by Wilcoxon signed ranks for pairwise comparisons at different evaluation times (pretreatment, 1 and 5 years). A Holm-Bonferroni (HB) correction method was used to control the familywise error rate, while $\mathrm{HB}$ is calculated by the equation $\mathrm{HB}=$ Target $n$-rank +1 ), where $n$ is the number of tests and the rank is the rank number of pair (by degree of significance).

\section{Results}

Two patients were dropped out during the follow-up period (one was unable to attend the follow-up period and the other due to loss of communication). Accordingly, $108 \mathrm{mini}$ implants, placed in 27 patients, were monitored for mini implant condition based on the predescribed criteria.

\section{Vertical Bone Level Changes}

Data were segregated according to mini implant positions and status (-Table 2). According to the predescribed ranking criteria, 98 mini implant were successful, three were satisfactory survival, four compromised survival while five mini implants failed in four different patients. The overall survival rate was calculated and presented after 5 years of treatment to be $90.7 \%$.

The data of the peri-implant bone height changes throughout the study periods were normally distributed so the mean value and standard deviations were calculated. The mean of

Table 1 Criteria of ranking mini-implants and number of the mini-implant in each category and location based on ICOI predescribed criteria

\begin{tabular}{|l|l|l|l|l|}
\hline & Criteria & \multicolumn{2}{|c|}{ Mini-implant location } & \multirow{2}{*}{ Total } \\
\cline { 3 - 4 } & & Anterior & Posterior \\
\hline Failed & $\begin{array}{l}\text { Loss, fractured, mobile, painful during function or vertical bone } \\
\text { loss exceeding half of the implant body length. }\end{array}$ & 1 & 4 \\
\hline Compromised survival & $\begin{array}{l}\text { Minimal clinical mobility, vertical bone loss less than half of the } \\
\text { implant body length or sensitivity during function. }\end{array}$ & 1 & 3 \\
\hline Satisfactory survival & $\begin{array}{l}\text { Bone loss more than two threads, but less than half of the } \\
\text { implant body length. }\end{array}$ & 0 & 3 \\
\hline Successful & Loss of less than two threads with no clinical significance. & 53 & 3 \\
\hline
\end{tabular}

Abbreviation: ICOI, International Congress of Oral Implantology. 
the vertical bone loss of the mini implants placed anteriorly (closer to the symphyseal area; $1.202 \pm 0.506$ ) was less than those placed posteriorly $(1.958 \pm 0.371)$ with a significant difference (0.032) at $p<0.05$ (-Fig. 3).

The mean of the peri-implant bone height changes at 1 month, 1,3 , and 5 years were $0.224 \pm 0.184,1.361 \pm 0.166$, $1.466 \pm 0.371$, and $1.61 \pm 0.371 \mathrm{~mm}$, respectively (-Table 2 ).

The difference between different assessment times was calculated by Bonferroni post-hoc test and the results showed a statistically significant difference between $1 \mathrm{~m}$ and all other assessment times. On the other hand, no significant difference was observed among bone loss at 1, 3, and 5 years, respectively (-Table 2 ).

\section{Oral Health Impact Profile}

Oral health-related quality of life using OHIP-14 was collected and both domain values and overall score at different assessment time were calculated. The data were nonparametric as calculated by Shapiro-Wilk test and the median values of the seven domains of the study as well as overall scores at their respective time, i.e., pretreatment, 1 , and 5 years were calculated ( - Table 3 ).

Based on the descriptive analysis, values of medians of all questionnaire domains were higher for paired evaluations between pretreatment and all posttreatment evaluations while several matched paired evaluations were seen between posttreatment evaluation times ( 1 and 5 years) ( - Fig. 3 ).

Table 2 Mean and standard deviation of bone loss for each time point and difference between several assessment times throughout the study period

\begin{tabular}{|l|l|l|l|l|}
\hline & $\begin{array}{l}\text { Mean and standard } \\
\text { deviation }\end{array}$ & $\mathbf{1} \mathbf{y}$ & $\mathbf{3} \mathbf{y}$ & $\mathbf{5}$ \\
\hline 1 month $(1 \mathrm{mo})$ & $0.224 \pm 0.184$ & $p<0.05^{\mathrm{a}}$ & $p<0.05^{\mathrm{a}}$ & $p<0.05^{\mathrm{a}}$ \\
\hline 1 year $(1 \mathrm{y})$ & $1.361 \pm 0.166$ & & 0.054 & 0.071 \\
\hline 3 years $(3 \mathrm{y})$ & $1.466 \pm 0.371$ & & & 0.102 \\
\hline 5 years $(5 \mathrm{y})$ & $1.61 \pm 0.371$ & & & \\
\hline
\end{tabular}

${ }^{a}$ Considered significant at $p<0.05$.

Table 3 Descriptive statistical values calculated for compared pairs inside different domains of the (OHIP-14) questionnaire

\begin{tabular}{|c|c|c|c|c|c|c|c|c|}
\hline & & Mean & SD & Minimum & Maximum & & Percentil & \\
\hline & & & & & & 25th & $\begin{array}{l}\text { 50th } \\
\text { (Median) }\end{array}$ & 75th \\
\hline $\mathrm{D} 1^{\mathrm{a}}$ & preD1 & 4.26 & 0.94 & 3.00 & 7.00 & 4.00 & 4.00 & 4.00 \\
\hline & Dyear1 & 2.00 & 2.27 & 0.00 & 7.00 & 0.00 & 1.00 & 4.00 \\
\hline & Dyear5 & 2.15 & 2.18 & 0.00 & 7.00 & 0.00 & 1.00 & 4.00 \\
\hline D2 & preD2 & 4.37 & 1.36 & 2.00 & 8.00 & 4.00 & 4.00 & 4.00 \\
\hline & D2y1 & 3.41 & 1.78 & 2.00 & 8.00 & 2.00 & 3.00 & 4.00 \\
\hline & D2y5 & 3.37 & 1.78 & 2.00 & 8.00 & 2.00 & 3.00 & 4.00 \\
\hline D3 & preD3 & 4.22 & 1.55 & 3.00 & 8.00 & 3.00 & 4.00 & 4.00 \\
\hline & D3y1 & 3.37 & 2.04 & 1.00 & 8.00 & 2.00 & 2.00 & 4.00 \\
\hline & D3y5 & 3.67 & 1.92 & 1.00 & 8.00 & 2.00 & 3.00 & 4.00 \\
\hline D4 & preD4 & 4.26 & 0.81 & 4.00 & 7.00 & 4.00 & 4.00 & 4.00 \\
\hline & D4y1 & 2.52 & 1.70 & 0.00 & 7.00 & 1.00 & 2.00 & 3.00 \\
\hline & D4y5 & 2.59 & 1.69 & 0.00 & 7.00 & 2.00 & 2.00 & 3.00 \\
\hline D5 & preD5 & 3.59 & 0.93 & 2.00 & 6.00 & 3.00 & 4.00 & 4.00 \\
\hline & D5y1 & 2.48 & 1.19 & 1.00 & 5.00 & 2.00 & 2.00 & 4.00 \\
\hline & D5y5 & 2.70 & 1.27 & 1.00 & 6.00 & 2.00 & 2.00 & 4.00 \\
\hline D6 & preD6 & 4.22 & 0.85 & 3.00 & 7.00 & 4.00 & 4.00 & 4.00 \\
\hline & D6y1 & 2.26 & 1.63 & 0.00 & 7.00 & 1.00 & 2.00 & 3.00 \\
\hline & D6y5 & 2.30 & 1.61 & 0.00 & 7.00 & 1.00 & 2.00 & 3.00 \\
\hline D7 & preD7 & 3.89 & 0.58 & 2.00 & 5.00 & 4.00 & 4.00 & 4.00 \\
\hline & D7y1 & 1.44 & 1.48 & 0.00 & 5.00 & 0.00 & 1.00 & 2.00 \\
\hline & D7y5 & 1.63 & 1.36 & 0.00 & 5.00 & 1.00 & 2.00 & 2.00 \\
\hline
\end{tabular}

Abbreviations: OHIP-14, oral health impact profile 14; pre, pretreatment; SD, standard deviation; y1, evaluation after 1 year, y5, evaluation after 5 year. DD1: D7, questionnaire domains. 


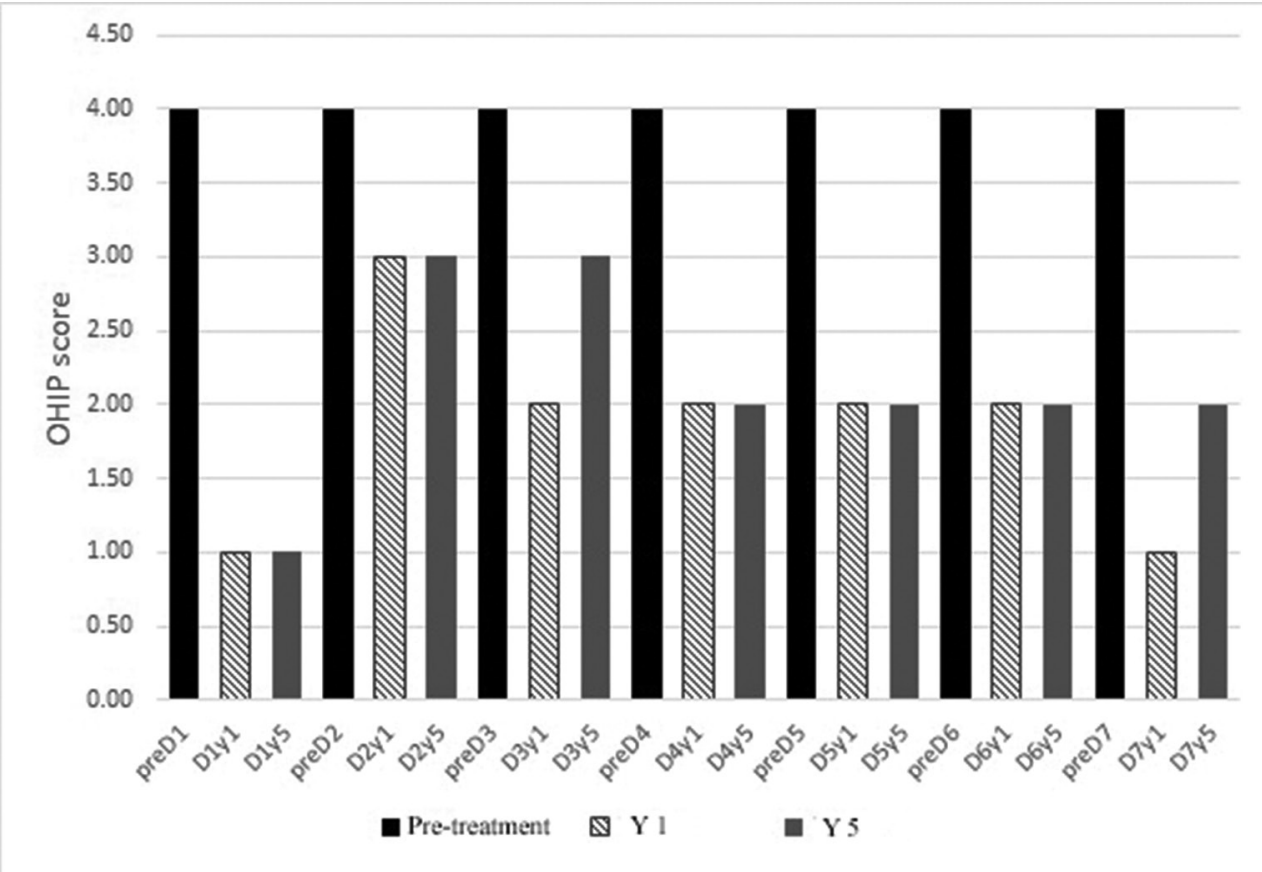

Fig. 3 Representative of the calculated median values of the (OHIP-14) seven domains at different times of patients' evaluation (pre = pretreatment, 1 year and 5 years). OHIP-14, oral health impact profile 14.

Table 4 Representative of the multiple paired comparisons of the seven studied questionnaire domains before treatment, after 1 year of treatment and after 5 years of treatment

\begin{tabular}{|c|c|c|c|c|c|c|}
\hline Test statistics & $\begin{array}{l}\text { Multiple paired } \\
\text { comparisons }\end{array}$ & $Z$ & $\begin{array}{l}\text { Asymp. Sig. } \\
\text { (two-tailed) }\end{array}$ & Rank & HB correction & Sig. \\
\hline \multirow[t]{3}{*}{ D1 } & Dyear1-preD1 & $-3.970^{\mathrm{b}}$ & 0.0001 & 8 & 0.0036 & $\mathrm{a}$ \\
\hline & Dyear5-preD1 & $-3.973^{b}$ & 0.0001 & 7 & 0.0033 & $\mathrm{a}$ \\
\hline & Dyear5-Dyear1 & $-1.633^{c}$ & 0.1025 & 18 & 0.0125 & NS \\
\hline \multirow[t]{3}{*}{ D2 } & D2y1-preD2 & $-3.640^{b}$ & 0.0003 & 12 & 0.0050 & a \\
\hline & D2y5-preD2 & $-3.739^{b}$ & 0.0002 & 11 & 0.0045 & a \\
\hline & D2y5-D2y1 & $-1.000^{b}$ & 0.3173 & 20 & 0.0250 & NS \\
\hline \multirow[t]{3}{*}{ D3 } & D3y1-preD3 & $-3.906^{b}$ & 0.0001 & 9 & 0.0038 & $\mathrm{a}$ \\
\hline & D3y5-preD3 & $-2.765^{b}$ & 0.0057 & 14 & 0.0063 & $\mathrm{a}$ \\
\hline & D3y5-D3y1 & $-2.271^{c}$ & 0.0231 & 15 & 0.0071 & NS \\
\hline \multirow[t]{3}{*}{ D4 } & D4y1-preD4 & $-4.168^{b}$ & 0.0000 & 5 & 0.0029 & $\mathrm{a}$ \\
\hline & D4y5-preD4 & $4.093^{b}$ & 0.0000 & 6 & 0.0031 & a \\
\hline & D4y5-D4y1 & $-1.414^{c}$ & 0.1573 & 19 & 0.0167 & NS \\
\hline \multirow[t]{3}{*}{ D5 } & D5y1-preD5 & $-3.800^{b}$ & 0.0001 & 10 & 0.0042 & $\mathrm{a}$ \\
\hline & D5y5-preD5 & $-3.624^{b}$ & 0.0003 & 13 & 0.0056 & a \\
\hline & D5y5-D5y1 & $-2.121^{c}$ & 0.0339 & 16 & 0.0083 & NS \\
\hline \multirow[t]{3}{*}{ D6 } & D6y1-preD6 & $-4.234^{b}$ & 0.0000 & 4 & 0.0028 & a \\
\hline & D6y5-preD6 & $-4.240^{b}$ & 0.0000 & 3 & 0.0026 & a \\
\hline & D6y5-D6y1 & $-1.000^{c}$ & 0.3173 & 20 & 0.0250 & NS \\
\hline \multirow[t]{3}{*}{ D7 } & D7y1-preD7 & $-4.276^{b}$ & 0.0000 & 2 & 0.0025 & $\mathrm{a}$ \\
\hline & D7y5-preD7 & $-4.285^{b}$ & 0.0000 & 1 & 0.0024 & a \\
\hline & D7y5-D7y1 & $-1.890^{c}$ & 0.0588 & 17 & 0.0100 & NS \\
\hline
\end{tabular}

Abbreviations: D, dimension; HB, Holm-Bonferroni; NS, not specified; pre, pretreatment; sig., significance; y, year.

aWilcoxon signed ranks test.

bbased on positive ranks.

cbased on negative ranks. 
The domains of the questionnaire were tested with the Wilcoxon signed ranks test after correction of the value $(0.05)$ using HB method to calculate the significance of the change of each domain during different evaluation times ( - Table 4).

The difference between the questionnaire domains' score at several evaluation times showed a significant reduction in the score levels between pretreatment and after 1 year of treatment as well as after 5 years of treatment. Based on the rank of the significance score, the most affected domain was domain 7 followed by domain 6 (especially between pretreatment and at 5 years comparisons) while the least domain affected was domain 3 (between pretreatment and at 3 years comparisons). On the other hand, nonsignificance was seen between 1 st year and 5 th year after treatment ( - Table 4 ).

\section{Discussion}

We conducted this study to assess the vertical marginal bone loss around the mini implants of the mandibular mini implant overdenture and the oral health impact profile for a group of edentulous smokers over 5 years of follow-up period. This study hypothesized that there is a significant difference between different evaluation intervals.

Generally, our results showed that the use of mini implants enhanced the treatment outcome and could act as a definitive line of treatment throughout the follow-up period. In addition, the results also revealed a good quality of life for patients using mini implant overdentures and thus maintaining a satisfactory result after 5 years of service.

The present study monitored the vertical marginal bone loss for 5 years with a focus on influence of implant location, and changes overtime. The findings revealed that a gradual bone loss happened after the first year of management with no significant bone changes the years after. Total bone loss around implants in posterior positions was higher than that recorded in the anterior positions with a significant value. This finding confirms the higher biomechanical stress applied on the posterior implants. Mini implant overdenture has a complex biomechanical behavior that depends on various quality of supporting tissues (from mini implants to edentulous tissues). These findings coincide with several studies..$^{12,28-30}$ For example, Fatalla et al, ${ }^{28}$ confirmed the influence of mini implant number and location on the amount of stress expected. They found higher stress values on the posterior implants than anterior implants in the parasymphyseal area. In the same context, Yoo et al, ${ }^{29}$ clarified the role of denture extension at the posterior area in increasing posterior implants' strain during function.

Regarding the marginal bone loss which occurred over time, a higher bone loss $(1.361 \pm 0.166 \mathrm{~mm})$ happened in the first year of implant placement and this loss diminished later (0.12: $0.25 \mathrm{~mm})$ to reach $(1.16 \pm 0.371 \mathrm{~mm})$ after 5 years. Therefore, vertical bone in the present study was close from expected bone loss at first year and even in the years after. ${ }^{3,11,15,26,28}$ However, more bone loss was expected after the first year especially in this smokers' cohort and at 5 years of overdenture service. The present results could be claimed to the frequent maintenance and follow-up which was essential to keep bone loss within the acceptable limit. Second, many articles explained the hazards of smoking on the peri-implant tissues and their integration but there are many other confounding factors in the clinical conditions that may contribute to the treatment's outcome..$^{6-11,15}$ Few studies separated successfully the effect of these confounding factors. . $^{70}$ Finally, the difference between the treatment options applied by our study and other studies may play a role in the final results. Specifically, overdenture is easy to be cleaned and maintained and posterior ridge could aid in the support.

Study of the OHRQoL using OHIP-14 questionnaire showed a significant reduction in the OHIP-14 score after 1 year of treatment. This means a significant improvement and enhancement of the patients' quality of life was appreciated and expressed in the questionnaire. Mini implant overdenture could maintain the improvement in the quality of life for 5 years after treatment as expressed statistically by the significance of the OHIP-14 scores between the first and fifth years of evaluations' scores. These findings clarified the value of using mini implants in stabilizing mandibular complete dentures and improve the patients' overall treatment experience. In addition, they confirmed the limitation of the complete denture and how much mini implants could restore the normal functioning of the smoking patients. These findings coincide with several researches encompassing mini implant overdenture satisfaction. ${ }^{17-20,22}$ Our research also agreed with Elsyad ${ }^{19}$ study, who checked patients' satisfaction over 5 years of follow-up. He also confirmed that mini implant mandibular overdentures maintained patient satisfaction after 5 years and added that this treatment required a considerable care of prosthetic maintenance and repair after 5 years of service.

Fully edentulous patient with chronic smoking habit is a compromised condition which is hard to maintain a satisfactory quality of life. Mini implant is a suitable option and could be used as a long-term treatment option for these patients if other conditions were favorable. Moreover, mini implants had beneficial characteristics over conventional implants like ease of use, suitability for reduced bone width, lower cost, and long-term successful outcome. ${ }^{26,31}$ The present study showed that smoker patients could use mini implant overdenture as a long-term stable line of treatment and it might be considered a standard health care for these patients.

The present study had its limitations including checking volumetric peri-implant bony changes, increasing the population size, and soft tissues changes surrounding mini implants. These limitations keep a space for further studies and chances to study different mini implant systems, attachment types, and different numbers and distribution of mini implants beneath the overdenture.

\section{Conclusion}

Within the limitations of this study, mandibular mini implants overdenture could keep satisfactory oral health quality of life, as measured by the OHIP-14, and an acceptable 
marginal peri-implant bone level for completely edentulous smokers after 5-years of follow-up period.

\section{Conflict of Interest}

None declared.

\section{Acknowledgment}

The authors would like to thank the colleagues in Oral and Maxillofacial Department and Research Center for their technical support and encouragement.

\section{References}

1 Kanazawa M, Feine J, Esfandiari S. Clinical guidelines and procedures for provision of mandibular overdentures on 4 mini-dental implants. J Prosthet Dent 2017;117(1):22-27

2 Marcello-Machado RM, Faot F, Schuster AJ. Nascimento GG, Del Bel Cury AA. Mini-implants and narrow diameter implants as mandibular overdenture retainers: a systematic review and meta-analysis of clinical and radiographic outcomes. J Oral Rehabil 2018;45(2):161-183

3 Misch CE, Dental Implant Prosthetics. 2nd ed. Missouri: Elsevier Health Sciences, Mosby 2014

4 Flanagan D, Mascolo A. The mini dental implant in fixed and removable prosthetics: a review. J Oral Implantol 2011;37(1):123-132

5 Bidra AS, Almas K. Mini implants for definitive prosthodontic treatment: a systematic review. J Prosthet Dent 2013;109(3):156-164

6 Chrcanovic BR, Albrektsson T, Wennerberg A. Smoking and dental implants: a systematic review and meta-analysis. J Dent 2015;43(5):487-498

7 Alfadda SA. Current evidence on dental implants outcomes in smokers and nonsmokers: a systematic review and meta-analysis. J Oral Implantol 2018;44(5):390-399

8 De Angelis F, Papi P, Mencio F, Rosella D, Di Carlo S, Pompa G. Implant survival and success rates in patients with risk factors: results from a long-term retrospective study with a 10 to 18 years follow-up. Eur Rev Med Pharmacol Sci 2017;21(3):433-437

9 Ponnaiyan D, Chillara P, Palani Y. Correlation of environmental tobacco smoke to gingival pigmentation and salivary alpha amylase in young adults. Eur J Dent 2017;11(3):364-369

10 Schwartz-Arad D, Samet N, Samet N, Mamlider A. Smoking and complications of endosseous dental implants. J Periodontol 2002;73(2):153-157

11 Peñarrocha M, Palomar M, Sanchis JM, Guarinos J, Balaguer J. Radiologic study of marginal bone loss around 108 dental implants and its relationship to smoking, implant location, and morphology. Int J Oral Maxillofac Implants 2004;19(6):861-867

12 Mundt T, Schwahn C, Biffar R, Heinemann F. Changes in bone levels around mini-implants in edentulous arches. Int $\mathrm{J}$ Oral Maxillofac Implants 2015;30(5):1149-1155

13 Kovačić I, Peršić S, Kranjčić J, Čelebić A. A cohort study on short mini-implants for mandibular overdentures compared to those of standard length. Clin Oral Implants Res 2020;31(2):121-132

14 Stoker G, van Waas R, Wismeijer D. Long-term outcomes of three types of implant-supported mandibular overdentures in smokers. Clin Oral Implants Res 2012;23(8):925-929

15 Van Doorne L, De Kock L, De Moor A, et al. Flaplessly placed 2.4$\mathrm{mm}$ mini-implants for maxillary overdentures: a prospective multicentre clinical cohort study. Int J Oral Maxillofac Surg 2020;49(3):384-391

16 Elemek E, Agrali OB, Kuru B, Kuru L. Peri-implantitis and severity level. Eur J Dent 2020;14(1):24-30

17 Preoteasa E, Imre M, Preoteasa CT. A 3-year follow-up study of overdentures retained by mini-dental implants. Int J Oral Maxillofac Implants 2014;29(5):1170-1176

18 Tomasi C, Idmyr BO, Wennström JL. Patient satisfaction with mini-implant stabilised full dentures. A 1-year prospective study. J Oral Rehabil 2013;40(7):526-534

19 Elsyad MA. Patient satisfaction and prosthetic aspects with mini-implants retained mandibular overdentures. A 5-year prospective study. Clin Oral Implants Res 2016;27(7):926-933

20 Catalán A, Martínez A, Marchesani F, González U. Mandibular overdentures retained by two mini-implants: a seven-year retention and satisfaction study. J Prosthodont 2016;25(5):364-370

21 Michaud PL, de Grandmont P, Feine JS, Emami E. Measuring patient-based outcomes: is treatment satisfaction associated with oral health-related quality of life? J Dent 2012;40(8):624-631

22 Siadat H, Alikhasi M, Mirfazaelian A, Geramipanah F, Zaery F. Patient satisfaction with implant-retained mandibular overdentures: a retrospective study. Clin Implant Dent Relat Res 2008;10(2):93-98

23 Kuoppala R, Näpänkangas R, Raustia A. Quality of life of patients treated with implant-supported mandibular overdentures evaluated with the oral health impact profile (OHIP-14): a survey of 58 patients. J Oral Maxillofac Res 2013;4(2):e4

24 ELsyad MA, Elgamal M, Mohammed Askar O, Youssef Al-Tonbary G. Patient satisfaction and oral health-related quality of life (OHRQoL) of conventional denture, fixed prosthesis and milled bar overdenture for All-on-4 implant rehabilitation. A crossover study. Clin Oral Implants Res 2019;30(11):1107-1117

25 Šćepanović M, Todorović A, Marković A, et al. Immediately loaded mini dental implants as overdenture retainers: 1-year cohort study of implant stability and peri-implant marginal bone level. Ann Anat 2015;199:85-91

26 Kullman L, Al-Asfour A, Zetterqvist L, Andersson L. Comparison of radiographic bone height assessments in panoramic and intraoral radiographs of implant patients. Int J Oral Maxillofac Implants 2007;22(1):96-100

27 Misch CE, Perel ML, Wang H-L, et al. Implant success, survival, and failure: the International Congress of Oral Implantologists (ICOI) pisa consensus conference. Implant Dent 2008;17(1):5-15

28 Fatalla AA, Song K, Du T, Cao Y. A three-dimensional finite element analysis for overdenture attachments supported by teeth and/or mini dental implants. J Prosthodont 2012;21(8):604-613

29 Yoo JS, Kwon K-R, Noh K, Lee H, Paek J. Stress analysis of mandibular implant overdenture with locator and bar/clip attachment: comparative study with differences in the denture base length. J Adv Prosthodont 2017;9(3):143-151

30 Ebadian B, Mosharraf R, Khodaeian N. Effect of cantilever length on stress distribution around implants in mandibular overdentures supported by two and three implants. Eur J Dent 2016;10(3):333-340

31 de Souza RF, Ribeiro AB, Della Vecchia MP, et al. Mini vs. standard implants for mandibular overdentures: a randomized trial. J Dent Res 2015;94(10):1376-1384 